\title{
A Study on the Literacy of Multicultural Family Children with Underachievement and Cognitive-Linguistic Variables Using the Korean Test of Literacy Diagnosis
}

\author{
Hye-Won Jung1), Soon-Gil Park2), Jeung-Ryeul Cho'3)
}

\begin{abstract}
This study aims to identify cognitive-linguistic variables affecting the literacy of multicultural family children with underachievement. The study subjects were 27 multicultural family children who were first and second grade elementary school students living in Jeollanam-do Province and the city of Gwangju. They were receiving special study guidance in reading and writing at community child centers. The research instrument used in the study was the Korean Test of Literacy Diagnosis (K-TOLD) [1]. The results of the analysis are as follows. First, multicultural family children with underachievement received mean scores of 27.00 in reading, 4.22 in writing and 23.77 in reading fluency. Second, phonological awareness and morphological awareness were found to be correlated with the literacy of the multicultural family children with underachievement. Third, naming speed and orthographic awareness were found to be the predicting variables of the literacy of the multicultural family children with underachievement. This suggests that multicultural family children with underachievement have reading and writing problems at a more basic level than grapheme-phoneme correspondences. Therefore, in terms of reading and writing, new approaches that are different from those provided to general children or underachievers should be developed for multicultural family children with underachievement, and a variety of intervention programs need to be developed for them through diagnosis of reading and writing.
\end{abstract}

Keywords: Multicultural Family, Literacy, Reading Fluency, Naming Speed, Orthographic Awareness

\section{Introduction}

Literacy, the ability to read and write, is an essential element for school-age children. It is an important area in the elementary education course, and is also important for students to

Received(April 20, 2019), Review Result(1st: May 13, 2019, 2nd: July 4, 2019), Accepted(September 10, 2019)

1) (Student) 62271 Nambu Univ., 23 Chumdan Jungang-ro, Gwangsan-gu, Gwangju, South Korea email: 09bbang@hanmail.net

2) (Professor, Corresponding Author) 62271 Dept. of Elementary Special Education, Nambu Univ., 23 Chumdan Jungang-ro, Gwangsan-gu, Gwangju, South Korea

email: psoongil@nambu.ac.kr

3) (Professor) 51767 Dept. of Psychology, Kyungnam Univ., Masanhappo-gu Kyungnamdaehag-ro 7 Changwon, South Korea

email: jrcho@kyungnam.ac.kr 
A Study on the Literacy of Multicultural Family Children with Underachievement and CognitiveLinguistic Variables Using the Korean Test of Literacy Diagnosis

understand textbooks. If a child cannot appropriately develop literacy, which is the basic skill for learning, the learning gap will increase as the child moves on to the next grade. For this reason, support for literacy is necessary for appropriate academic achievement[2-4].

Multicultural family children have been reported to have lower abilities in reading, writing, vocabulary and composition than those of general children, rather than experiencing many communication difficulties in daily life[5]. It was found that one of their major difficulties with the Korean language is difficulty in literacy, the ability to read and write[4][6]. And literacy difficulty leads to academic underachievement. Not all multicultural family children experience academic underachievement, but their difficulties are different to some extent from those of general students with underachievement. Therefore, education support should be provided for them in consideration of their circumstances.

As there is a growing interest in interventions and education related to reading, a number of studies have been conducted to identify variables related to reading. Children with underachievement exhibited lower literacy performance than that of general students, and that the predictor variables include phonemic awareness, short-term memory, naming speed, visual figure-ground perception and morphemes[7]. A some studies found that for second grade elementary school students, predictor variables affecting reading are phonemic awareness and syllable awareness [8] another study examined the characteristics of reading fluency by analyzing reading speed, error frequency and error types of multicultural family children who were first and second grade elementary school students [5] and [4] found that learning therapy is effective for improving reading and writing abilities after conducting it on children with underachievement. If lower-grade elementary school children have difficulties with phonological awareness, reading fluency and reading comprehension, they are highly likely to continue to have difficulties in upper grades. Therefore, what kind of problems children experience in the reading process needs to be examined.

Writing is the most complex and highest level skill among linguistic skills[9]. Basically, spelling ability should be developed prior to writing. Writing is one of the most frequent activities performed in lower grades of elementary school. If a child cannot develop basic writing skills during this period, the child will continue to have writing difficulties in upper grades. Some studies reported that when underachievers in reading were taught both reading and writing in a reading intervention program, their writing speed, fluency and accuracy improved[10]. There are studies that confirm that spelling errors related to grammatical morphemes increase among third grade students in elementary school, explaining that children continue to have spelling difficulties in mid grades of elementary school as they are required 
to write grapheme-phoneme non-correspondent words, acquire complex spelling knowledge and learn spellings using morpheme knowledge[11]. And [12] stated that children develop phonetic spelling knowledge fast as it is related to spelling words as they sound, while it takes a long time for them to develop morphemic spelling knowledge, and that spelling ability has a high correlation with phonological awareness ability. This shows the need for teaching writing in lower grades of elementary school, and a number of studies have reported that predictor variables affecting writing include phonological awareness, spelling knowledge, morphology knowledge and cognitive ability[7][13][14].

Although studies have been conducted to identify causes of reading and writing problems, there are insufficient studies on multicultural family children's reading and writing. They are not exposed to enough stimuli to learn Korean at young ages, and their limited linguistic ability causes difficulties in school life and learning. As they have the most difficulties with learning the Korean alphabet, or Hangeul, checking their reading and writing abilities can help reduce their problems related to learning ability.

There are some Korean studies conducted on multicultural family children. They include studies that examined the literacy ability of multicultural and low-income family children[6][13], studies on multicultural family children's reading fluency[5][15], and studies that examined the effect of a learning therapy program for multicultural family children[4]. However, there are insufficient studies that examined tests of multicultural family children's overall literacy; such studies need to be conducted so as to correctly identify and address reading and writing problems of multicultural family children with underachievement.

The Korean Test Of Literacy Diagnosis (K-TOLD) is a diagnostic instrument[1] to examine literacy and cognitive ability. The results of the test help determine types of academic underachievement and identify what kinds of cognitive-linguistic deficits children have. This test instrument can be used to find causes of academic underachievement by identifying various deficits and to teach children reading and writing to improve their abilities related to these skills.

This study intends to examine multicultural family children's literacy and cognitive-linguistic deficits using the K-TOLD[1], providing preliminary data for teaching Hangeul to multicultural family children with underachievement. The objective of this study is to examine literacy (reading, writing, reading fluency) of multicultural family children with academic underachievement and cognitive-linguistic variables (phonological awareness, naming speed, short-term memory, right-left reversal, orthographic awareness, morphological awareness) and identify predictor variables. Research questions of this study are as follows. 
A Study on the Literacy of Multicultural Family Children with Underachievement and CognitiveLinguistic Variables Using the Korean Test of Literacy Diagnosis

First, what are the mean scores of literacy and cognitive-linguistic variables of multicultural family children with underachievement?

Second, how the literacy of multicultural family children with underachievement and cognitive-linguistic variables are correlated?

Third, what variables affect the literacy of multicultural family children with underachievement?

\section{Research Methods}

\subsection{Study Subjects}

This study was conducted on 27 first and second grade elementary school students who lived in Jeollanam-do Province and the city of Gwangju and were receiving extra education at community child centers after school. They were born between Korean fathers and marriage migrant mothers. These multicultural family children were born and lived in Korea and spoke Korean as their first language. They had difficulties in learning reading and writing and were receiving special study guidance at community child centers. The directors of the centers reported that they did not have disabilities or visual, auditory, emotional and physical problems. Neither did they exhibit peer communication problems. [Table 1] shows general characteristics of the study subjects.

[Table 1] General Characteristics of the Study Subjects

\begin{tabular}{|c|c|c|}
\hline \multirow{2}{*}{ Characteristics } & Classification & $\mathrm{N}(\%)$ \\
\cline { 2 - 3 } & Grade 1 & $14(51.8)$ \\
\hline \multirow{2}{*}{ Grade } & Grade 2 & $13(48.2)$ \\
\cline { 2 - 3 } & Male & $10(37.1)$ \\
\hline \multirow{2}{*}{ Gender } & Female & $17(62.9)$ \\
\cline { 2 - 3 } $\begin{array}{c}\text { Community child } \\
\text { center }\end{array}$ & Center A & $13(48.2)$ \\
\cline { 2 - 3 } & Center B & $14(51.8)$ \\
\hline $\begin{array}{c}\text { Nationality of the } \\
\text { mother }\end{array}$ & Vietnamese & $12(44.5)$ \\
\cline { 2 - 3 } & Filipino & $9(33.3)$ \\
\hline
\end{tabular}

\subsection{Research Instrument}

\subsubsection{Literacy Test}


The word reading, dictation and reading fluency tests of the K-TOLD[1] were used in the literary test in this study. The word reading test consisted of a total of 96 questions. A correct answer was scored 1, and an incorrect answer 0 . And the test was stopped when there were five incorrect answers in a row.

The writing test consisted of a total of 35 questions, and children wrote down words read by the tester on sheets of paper. A correct answer was scored 1, and an incorrect answer 0 . And the test was stopped when there were three incorrect responses in a row.

In the reading fluency test, children were required to correctly and fast read 98 syllables in 40 seconds, and the time was measured using a stopwatch. The tester put a tick indicating a wrong answer on the recording paper for a syllable read incorrectly or not read, and a point was given for each syllable. Reading, writing and reading fluency tests are comprised of Type A and Type B; Type A was used in this study.

\subsubsection{Cognitive-Linguistic Variable Test}

In this study, The phonological awareness, naming speed, short-term memory, right-left reversal, orthographic awareness, morphological awareness tests of the K-TOLD[1] were used in the cognitive-linguistic variable test.

The phonological awareness test included three sub-tests: syllable deletion, final consonant deletion and initial consonant deletion tests. In the syllable deletion test, children were required to read a word or non-word of three to four syllables, by omitting one syllable. In the final consonant deletion test, they were required to read a word or non-word of one syllable, by omitting the final consonant. In the initial consonant deletion test, they were required to read a word or non-word of one syllable, by omitting the initial consonant.

The naming speed test consisted of two sub-tests: number naming and object naming tests. In the number naming test, the tester measured how long it took children to name 25 words. In the object naming test, the tester measured how long it took children to name 25 words.

The short-term memory test included two sub-tests: number and syllable short-term memory tests. The right-left reversal test consisted of a total of 80 items about numbers, vowels/consonants, letters and the English alphabet. Children were required to find correct ones among a mix of right-left reversed and correct items, and the tester checked if they picked correct ones. The orthographic awareness test consisted of a total of 80 items, and children were required to find words among correctly spelled words and misspelled non-words. The morphological awareness test was to see to what degree children could understand meanings of letters and syllables and manipulate them; children were required to make new 
A Study on the Literacy of Multicultural Family Children with Underachievement and CognitiveLinguistic Variables Using the Korean Test of Literacy Diagnosis

compound words, using morphemes they knew.

\subsection{Research Procedure and Data Processing}

The research was conducted on children who were enrolled in community child centers located in the city of Gwangju and Jeollanam-do Province during the period from September 2018 to November 2018. The researchers explained the purpose of the test to the directors of the centers and obtained consent from the children's parents. The researchers visited the centers, and one-on-one tests were conducted in separate rooms.

Data was processed and analyzed using the SPSS 18.0 Windows program as follows. First, T-test was conducted to examine differences between groups in terms of literacy and cognitive-linguistic variables. Second, the Pearson correlation analysis was used to examine correlations between literacy and cognitive-linguistic variables. Third, a regression analysis was conducted to identify predictor variables of literary for each group.

\section{Results of the Research}

\subsection{Comparing Means Scores of Literacy and Cognitive-Linguistic Variables}

[Table 2] shows mean scores of literacy (reading, writing, reading fluency) and cognitive-linguistic variables (phonological awareness, naming speed, short-term memory, right-left reversal, orthographic awareness, morphological awareness) of the multicultural family children.

[Table 2] Mean Scores and Standard Deviations of Literacy and Cognitive-Linguistic Variables

\begin{tabular}{|c|c|c|c|c|c|}
\hline \multicolumn{2}{|r|}{ Variables } & $\mathrm{M}$ & SD & Minimum & Maximum \\
\hline \multirow{3}{*}{ Literacy } & Reading (96) & 27.00 & 15.24 & 12.00 & 58.00 \\
\hline & Writing (35) & 4.22 & 2.81 & 1.00 & 11.00 \\
\hline & Reading fluency (98) & 23.77 & 15.47 & 0.00 & 49.00 \\
\hline \multirow{3}{*}{$\begin{array}{c}\text { Phonologic } \\
\text { al } \\
\text { awareness }\end{array}$} & Syllable deletion (18) & 5.77 & 3.66 & 3.00 & 12.00 \\
\hline & Final consonant deletion (18) & 6.22 & 5.56 & 1.00 & 16.00 \\
\hline & Initial consonant deletion (18) & 3.33 & 1.50 & 1.00 & 5.00 \\
\hline \multirow{2}{*}{$\begin{array}{l}\text { Naming } \\
\text { speed }\end{array}$} & Number naming (sec.) & 16.94 & 3.56 & 11.00 & 23.00 \\
\hline & Object naming (sec.) & 32.05 & 10.03 & 25.00 & 57.00 \\
\hline Short-term & Number memory (24) & 9.66 & 2.12 & 6.00 & 13.00 \\
\hline
\end{tabular}


Vol.5, No.3, September 30 (2019), pp. 41-51 http://dx.doi.org/10.21742/apjcri.2019.09.05

\begin{tabular}{|c|c|c|c|c|c|}
\hline memory & Syllable memory (24) & 9.11 & 2.02 & 6.00 & 12.00 \\
\hline- & Left-right reversal (80) & 55.88 & 20.36 & 11.00 & 72.00 \\
\hline- & Orthographic awareness (80) & 38.55 & 7.45 & 26.00 & 50.00 \\
\hline- & Morphological awareness (25) & 6.88 & 4.10 & 1.00 & 14.00 \\
\hline
\end{tabular}

As shown in Table 2, in the literacy sector, the mean score of reading was 27.00, that of writing was 4.22 and that of reading fluency was 23.77 seconds. As for phonological awareness, the children performed best in the final consonant deletion at 6.22. With regards to naming speed, the children were faster with number naming $(\mathrm{M}=16.94)$ than with object naming $(\mathrm{M}=32.05)$. In terms of short-term memory, the children performed best in number memory $(\mathrm{M}=9.66)$. And the scores were 55.88 in right-left reversal, 38.55 in orthographic awareness, and 6.88 in morphological awareness.

\subsection{Correlations between Literacy and Cognitive-Linguistic Variables}

[Table 3] shows the correlations between literacy and cognitive-linguistic variables among the multicultural family children.

[Table 3] Correlations between Literacy and Cognitive-Linguistic Variables

\begin{tabular}{|c|c|c|c|c|c|c|c|c|c|}
\hline Variable & Reading & Writing & $\begin{array}{c}\text { Reading } \\
\text { fluency }\end{array}$ & $\begin{array}{c}\text { Overall } \\
\text { literacy }\end{array}$ & $\begin{array}{c}\text { Phonologica } \\
\text { l awareness }\end{array}$ & $\begin{array}{c}\text { Naming } \\
\text { speed }\end{array}$ & $\begin{array}{c}\text { Short-term } \\
\text { memory }\end{array}$ & $\begin{array}{c}\text { Right-left } \\
\text { reversal }\end{array}$ & $\begin{array}{c}\text { Orthograp } \\
\text { hic } \\
\text { awareness }\end{array}$ \\
\hline Writing & .25 & & & & & & & & \\
\hline $\begin{array}{c}\text { Reading } \\
\text { fluency }\end{array}$ & $-.50^{* *}$ & .01 & & & & & & & \\
\hline $\begin{array}{c}\text { Overall } \\
\text { literacy }\end{array}$ & $.91^{* *}$ & $.40^{*}$ & $.59^{* * *}$ & & & & & & \\
\hline $\begin{array}{c}\text { Phonological } \\
\text { awareness }\end{array}$ & $.53^{* *}$ & $.41^{*}$ & .21 & $.57^{* * *}$ & & & & & \\
\hline $\begin{array}{c}\text { Naming } \\
\text { speed }\end{array}$ & $.42^{*}$ & .08 & .18 & .33 & .23 & & & & \\
\hline $\begin{array}{c}\text { Short-term } \\
\text { memory }\end{array}$ & .20 & -.01 & .01 & .20 & -.04 & -.63 & & & \\
\hline $\begin{array}{c}\text { Right-left } \\
\text { reversal }\end{array}$ & $.36^{*}$ & .29 & .29 & .32 & .13 & .31 & .11 & & \\
\hline $\begin{array}{c}\text { Orthographic } \\
\text { awareness }\end{array}$ & .17 & .12 & -.05 & .14 & .10 & -.18 & -.05 & .10 & \\
\hline $\begin{array}{c}\text { Morphologic } \\
\text { al awareness }\end{array}$ & $.55^{* * *}$ & -.14 & .33 & $.44^{*}$ & $.43^{*}$ & .10 & -.08 & -.01 & .02 \\
\hline
\end{tabular}

${ }^{*} \mathrm{p}<.05,{ }^{* *} \mathrm{p}<.01,{ }^{* * *} \mathrm{p}<.001$ 
A Study on the Literacy of Multicultural Family Children with Underachievement and Cognitive-Linguistic Variables Using the Korean Test of Literacy Diagnosis

As shown in [Table 3], it was found that reading had a statistically significant correlation with phonological awareness $(r=-.53, \mathrm{p}<.01)$, naming speed $(\mathrm{r}=.42, \mathrm{p}<.05)$, right-left reversal $(\mathrm{r}=.36, \mathrm{p}<.05)$, and morphological awareness $(\mathrm{r}=.55, \mathrm{p}<.001)$. Writing was found to be correlated with phonological awareness $(\mathrm{r}=.41, \mathrm{p}<.05)$. Reading fluency was found to have no correlation with any variables. Overall literacy were correlated with phonological awareness $(r=.57, \mathrm{p}<.001)$ and morphological awareness $(\mathrm{r}=.44, \mathrm{p}<.05)$.

Therefore, phonological awareness and morpheme awareness were found to be correlated with the literacy of the multicultural family children.

\subsection{Predictor Variables of Literacy}

[Table 4] shows predictor variables affecting the literacy of the multicultural family children.

[Table 4] Predictor Variables of Literacy

\begin{tabular}{|c|c|c|c|c|c|c|c|c|}
\hline $\begin{array}{l}\text { Dependent } \\
\text { variable }\end{array}$ & Predictor variable & B & $\beta$ & $\mathrm{t}$ & $\mathrm{p}$ & $\mathrm{R}^{2}$ & $\triangle \mathrm{R}^{2}$ & $\mathrm{~F}$ \\
\hline \multirow{3}{*}{ Reading } & Constant & 65.92 & - & 6.59 & .000 & \multirow{3}{*}{.38} & \multirow{3}{*}{.19} & \multirow{3}{*}{2.06} \\
\hline & Naming speed & -25.27 & -.39 & -2.17 & .042 & & & \\
\hline & Orthographic awareness & -48.69 & -.59 & -2.53 & .020 & & & \\
\hline \multirow{2}{*}{ Reading fluency } & Constant & 46.57 & - & 6.51 & .000 & \multirow{2}{*}{.35} & \multirow{2}{*}{.16} & \multirow{2}{*}{1.86} \\
\hline & Naming speed & -16.97 & -.37 & -2.14 & .048 & & & \\
\hline
\end{tabular}

${ }^{*} \mathrm{p}<.05,{ }^{* *} \mathrm{p}<.01,{ }^{* * *} \mathrm{p}<.001$

As shown in [Table 4], the strongest predictor variables related to reading in descending order were orthographic awareness $(\beta=-.59, \mathrm{p}<.05)$ and naming speed $(\beta=-.39, \mathrm{p}<.05)$. These two variables explained $17 \%$ of reading $(\mathrm{F}=2.06, \mathrm{p}>.05)$. It was found that the predictor variable of reading fluency was naming speed $(\beta=-.37, p<.05)$, and this variable explained $16 \%$ of reading fluency $(\mathrm{F}=1.86, \mathrm{p}>$.05). There was no predictor variable of writing. Therefore, naming speed and orthographic awareness were the predictor variables of the literacy of the multicultural family children.

\section{Conclusion}

This study conducted Korean reading and writing diagnostic tests on multicultural family children with underachievement and analyzed the mean scores of literacy and 
cognitive-linguistic variables, correlations between literacy and cognitive-linguistic variables and predictor variables of literacy. The results of the analysis are as follows.

First, multicultural family children with underachievement received mean scores of 27.00 in reading, 4.22 in writing and 23.77 in reading fluency. They received a mean score of 27 out of 96, which is lower than 61.87, the mean score of multicultural family students in lower grades of elementary school reported in another study[13]. And they received a mean score of 4.22 out of 35 in writing. The score is lower than 14.65, the score reported in another study[13]. Therefore, it can be seen that multicultural family children with underachievement tend to have lower scores in reading and writing than those of general multicultural family children.

The reading fluency test examined how many syllables they could read correctly among the words of 98 syllables in 40 seconds. They read an average of 23.77 words correctly. The test was to measure the ability to correctly read words at an appropriate rhythm, and the difference can be explained by the fact that multicultural family children with underachievement need more time to correctly read or decipher words.

Second, phonological awareness and morphological awareness were found to be correlated with the literacy of the multicultural family children with underachievement. The results of this study support previous studies[1][7][10] as well as studies that reported multicultural family children exhibited lower performance in phonological awareness and morphological awareness than those of general children[6][16][17].

Third, naming speed and orthographic awareness were found to be the predicting variables of the literacy of the multicultural family children with underachievement. This is different from the founding of previous studies that phonological awareness is a variable affecting the literacy of general children[5][16][18]. This suggests that multicultural family children with underachievement have reading and writing problems at a more basic level than grapheme-phoneme correspondences.

In conclusion, in terms of reading and writing, new approaches that are different from those provided to general children or underachievers should be developed for multicultural family children with underachievement, and a variety of intervention programs need to be developed for them through diagnosis of reading and writing.

\section{Acknowledgement}

*This study was supported by research funds from Nambu University, 2019.

*This work was supported by the National Research Foundation of Korea Grant funded by the 
A Study on the Literacy of Multicultural Family Children with Underachievement and Cognitive-Linguistic Variables Using the Korean Test of Literacy Diagnosis

Korean Government (NRF-2016S1A2A2912359).

\section{References}

[1] Jeung-Ryeul Cho, Young-Suk, Soon-Gil Park, The Korean Test Of Literacy Diagnosis :K-TOLD, Korean Guidance, (2017)

[2] Soon-Ho Kim, Kyung-Hee Jung, Morphological Awareness and Reading Abilities for Early Elementary School Students with Poor Reading Skill, Journal of speech-language \& hearing disorders, (2015), Vol.24, No.2, pp.35-47, DOI: 10.15724/jslhd.2015.24.2.004

[3] Keung-Mi Son, A Study on Learning Lexicon of Multi-Cultural Household Elementary School Children, Korean Linguistics, (2012), Vol.55, pp.173-206, UCI: G704-000626.2012.55..006

[4] Eun-Sil Choi, Effect of Reading and Writing Abilities Improvement Program for Elementary School Children of Multicultural Families, The Journal of the Korea Contents Association, (2014), Vol.14, No.10, pp.393-402, DOI: $10.5392 /$ JKCA.2014.14.10.393

[5] Gou-ni Shim, Kyung Hee Jung, Reading Fluency of First and Second Grade Children from Multicultural Backgrounds, Journal of speech-language \& hearing disorders, (2012), Vol.21, No.2, pp.93-110, DOI: 10.15724/jslhd.2012.21.2.006

[6] Soon-Gil Park, Jeung-Ryeul Cho, Sun-Hee Park, Comparisons of Korean Literacy and Cognitive-Linguistic Skillsamong Preschool Children from Rural and UrbanCommunities and Multicultural Families, Journal of speech-language \& hearing disorders, (2014), Vol.23, No.4, pp.33-46, DOI: 10.15724/jslhd.2014.23.4.004

[7] Soon-Gil Park, A Study on the literacy of underachievers, The Journal of Special Children Education, (2012), Vol.14, No.2, pp.27-51, DOI: 10.21075/kacsn.2012.14.2.27

[8] Jeung-Ryeul Cho, Catheine McBride-Chang, Correlates of Korean Hangul Acquisition Among Kindergartners and Second Graders, Scientific Studies of Reading, (2005), Vol.9, No.1, pp.3-16, DOI: https://doi.org/10.1207/s1532799xssr0901_2

[9] Yoo-Jeong Kim, Ock-Ryeo, Kang, Peer Tutoring by a Senior Student with Imitation Strategy on the Writing Underachiever's and Peer Instructor's Writing Abilities, The Korea Journal of Learning Disabilities, (2016), Vol.13, No.3, pp.91-115, UCI: G704-SER000009008.2016.13.3.001

[10] Soon-Gil Park, You-Ri Choi, The Impacts of Reading Intervention Program on Literacy and Vocabulary of Students with Reading Difficulties, Journal of Special Education \& Rehabilitation Science, (2015), Vol.54, No.3, pp.195-212, DOI: 10.15870/jsers.2015.09.54.3.195

[11] Ga-Young Shin, Ah-Young Seol, Hye-Suk Cho, Ki-Chun Nam, So-Yeong Pae, Korean Spelling Development and Linguistic Patterns, Journal of speech-language \& hearing disorders, (2015), Vol.24, No.2, pp.61-72, DOI: 10.15724 /jslhd.2015.24.2.006

[12] Min-hwa Yang, Speech Perception of Mobile Telephone in Children with Cochlear Implants, Korean Journal of Special Education, (2006), Vol.41, No.3, pp.163-186, UCI: G704-000685.2006.41.3.007

[13] Soon-Gil Park, Jeung-Ryeul Cho, Eun-Hee Kim, A study on reading and writing and congnitive processing 
Vol.5, No.3, September 30 (2019), pp. 41-51 http://dx.doi.org/10.21742/apjcri.2019.09.05 from multicultural in elementary, Asia-pacific Journal of Multimedia Services Convergent with Art, Humanities, and Sociology, (2015), Vol.5, No.2, pp.157-165, DOI: 10.35873/ajmahs.2015.5.2.017

[14] Sang-Mi Kim, Jeung-Ryeul Cho, Ji-Youn Kim, Cross-language Transfer of Phonological Awareness and Its Relations with Reading and Writing in Korean and English, Korean Journal of Cognitive Science, (2015), Vol.26, No.2, pp.125-146, DOI: 10.19066/cogsci.2015.26.2.001

[15] Jun-Chae Yoon, Research on Multicultuarl Children's Reading Fluency, Jounal of Elementary Korean Education, (2012), No.48, pp.211-230, DOI: 10.22818/jeke.2012..48.211

[16] Hwa-Kyung Kim, So-Yeong Pae, Hyo-Jin Yoon, Decoding and Reading Fluency for Children from Low-Income Families, Journal of speech-language \& hearing disorders, (2013), Vol.22, No.1, pp.55-68, DOI: 10.15724/jslhd.2013.22.1.004

[17] Mi-Bae Kim, So-Yeong Pae, Reading Skills and Phonological Processing Abilities of Korean Elementary School Children with/without Poor Reading, Communication Sciences and Disorders, (2012), Vol.17, No.4, pp.565-581, UCI: G704-000725.2012.17.4.006

[18] Jeung-Ryeul Cho, Sung-Bong Bae, Hye-Won Park, Soon-Gil Park, The relations of cognitive-Linguistic skills with Literacy and mathematics skills among children Living in urban and rural communities, Korean Journal of Early Childhood Education, (2012), Vol.32, No.3, pp.357-381, DOI: 10.18023/kjece.2012.32.3.016 